2015

\title{
Paradigm Flaw in the Boardroom: Governance versus Management
}

Edward J. Waitzer

Osgoode Hall Law School of York University, ewaitzer@osgoode.yorku.ca

Alfredo Enrione

Follow this and additional works at: http://digitalcommons.osgoode.yorku.ca/olsrps

\section{Recommended Citation}

Waitzer, Edward J. and Enrione, Alfredo, "Paradigm Flaw in the Boardroom: Governance versus Management" (2015). Osgoode Legal Studies Research Paper Series. 91.

http://digitalcommons.osgoode.yorku.ca/olsrps/91 


\title{
OSGOODE HALL LAW SCHOOL LEGAL STUDIES RESEARCH PAPER SERIES
}

\section{Research Paper No. 15}

Vol. 11/ Issue. 03/ (2015)

\section{Paradigm flaw in the boardroom: Governance versus management}

\author{
Edward J. Waitzer \& Alfredo Enrione
}

Editors:

Editor-in-Chief: Carys J. Craig (Associate Dean of Research \& Institutional Relations and Associate Professor, Osgoode Hall Law School, York University, Toronto)

Production Editor: James Singh (Osgoode Hall Law School, York University, Toronto)

\footnotetext{
This paper can be downloaded free of charge from:

http://ssrn.com/abstract=2583613.
}

Further information and a collection of publications from the Osgoode Hall Law School Legal Studies Research Paper Series can be found at: 
Osgoode Legal Studies Research Paper No. 15

Vol. 11/ Issue. 03/ (2015)

\title{
Paradigm flaw in the boardroom: Governance versus management
}

\author{
Edward J. Waitzer \& Alfredo Enrione
}

\begin{abstract}
:
The purpose of this paper is to explore a more constructive role for corporate boards - one that would entail directors recognising the operational primacy of management and focusing their attention on the manner in which a corporation can best fulfil its long-term strategy. Paying more attention to nurturing long-term, sustainable value will help differentiate roles and will suggest the need for new metrics and a deeper appreciation by directors of corporate strategy and organisational capacity. At a time when senior management are dedicating disproportionate resources to immediate compliance issues, it is critical that boards take such a broad view.
\end{abstract}

\section{Keywords:}

Corporate governance, management, organisational capacity, sustainability

\author{
Author(s): \\ Edward J. Waitzer \\ Osgoode Hall Law School \\ York University, Toronto \\ E: ewaitzer@osgoode.yorku.ca \\ Alfredo Enrione \\ Universidad de los Andes, Chile \\ ESE Business School \\ E: aenrione@uandes.cl
}




\title{
Paradigm flaw in the boardroom: Governance versus management
}

\author{
Edward J. Waitzer \\ *Stikeman Elliott LLP \\ ewaitzer@stikeman.com
}

\begin{abstract}
Alfredo Enrione,
PwC professor of Corporate Governance at ESE Business School, Universidad de los Andes in Chile. aenrione@uandes.cl
\end{abstract}




\begin{abstract}
The purpose of this paper is to explore a more constructive role for corporate boards - one that would entail directors recognising the operational primacy of management and focusing their attention on the manner in which a corporation can best fulfil its long-term strategy. Paying more attention to nurturing long-term, sustainable value will help differentiate roles and will suggest the need for new metrics and a deeper appreciation by directors of corporate strategy and organisational capacity. At a time when senior management are dedicating disproportionate resources to immediate compliance issues, it is critical that boards take such a broad view.
\end{abstract}

KEYWORDS: corporate governance, management, .organisational capacity, sustain-ability

\title{
INTRODUCTION
}

This paper addresses the fact that in today's evolving corporate governance process actual performance may well be retarded by the rapid proliferation of intrusive regulatory requirements, zealous enforcement initiatives and the cottage industries that have grown up around them. Rather than address the 'emperor's clothes' phenomenon, such heightened regulatory attention to corporate governance has driven many further away from substantive improvements, largely because management and corporate directors have often responded by becoming more risk averse.

The emphasis on quarterly earnings at the expense of long-term growth has garnered significant attention in the last two decades. ${ }^{2}$ A new scholarship has arisen which has focused on the interests of the owners of the corporation which include, depending on one's point of view, shareholders and other stakeholders. ${ }^{3}$ Long-term value is readily distinguished from short-term returns often generated by managers who are incentivised by the time horizon of their compensation arrangements. In his retrospective on the first decade of what he terms the 'global corporate governance revolution', Stephen Davis recounts the wise comment once made by Harvard University President Larry Summers, that 'in the history of the world, no one has ever washed a rented car'. As with corporations themselves, far too much of people's savings are managed as if rented, rather than owned. Davis observes that, 'things go deeply amiss when owner passivity is so chronic'. 5

Although the business corporation is a relatively recent invention, ${ }^{6}$ it has coincided with and contributed significantly to the greatest quantum leap in economic history. ${ }^{7}$ After studying the history of human economic development, Goodfriend and MacDermott concluded that long-term economic development involves four fundamental processes: increasing returns through specialisation, a transition from household to market production, knowledge and human capital accumulation, and industrialisation. ${ }^{8}$ The creation of the business corporation enhanced all four factors. As Professor Margaret Blair points out, ${ }^{9}$ over the last two centuries the creation of the business corporation enhanced all four factors because 'it allowed the entrepreneurs and managers to "lock-in" the capital invested in the enterprise, thereby making it possible to invest in long-lived, highly specific assets'. Enterprise creation and growth were never again bounded to the ideas of high net worth individuals nor the limited resources available to those with administrative talent. New markets and criteria emerged for specialisation and knowledge accumulation: entrepreneurial ideas looking for resources, resources looking for ideas and 
individuals looking for jobs and proper rewards for their management talents.

Seen as a form evolving in relation to its changing environment, the corporation has been unsurpassed in its ability to effect rapid transformations of itself without flying apart at the seams, without disappearing as a form and often without loss of identity even at the level of the individual firm. Not surprisingly, such a potent instrument attracts high expectations. This precept is widely understood, but rarely acknowledged, by business leaders and their critics alike. It is particularly relevant today, when a key building block to more effective governance may well be moving beyond the increasingly singular focus on regulatory compliance (which often induces short-term, risk-averse conduct) to one that embraces longer-term, sustainable value creation.

The virtuous cycle - engaged, long-term shareholders encouraging responsive governance that is more likely to produce higher, sustainable returns, in turn attracting more engaged, long-term investors - remains far from commonplace. A shift in how directors think about their roles may help remedy this disturbing trend, which undermines the fundamental strength of the enterprise culture. The purpose of this paper is to explore a more meaningful and constructive role for directors, focusing on governance (versus management) and the longer term.

\section{GOVERNANCE VERSUS MANAGEMENT}

More than a decade ago, John Pound distinguished between the 'managed-corporation model' and the 'governed-corporation model'. ${ }^{10}$ The managed-corporation model is centred on power, with the role of the board of directors being to tighten control over (potentially) wayward managers. The model is a legacy of dispersed ownership and resulting agency problems. It has become exaggerated, of late, because of regulatory responses to highly publicised corporate scandals.

In fact (as Pound pointed out), most managers do not have excess power. Nor are most corporate failures the result of power imbalances. They more typically result from subtle flaws in managerial incentives and decision-making processes. While balancing powers is important, its relevance is tied to the creation of sustainable value through effective decision making.

In the managed-corporation model, directors (and shareholders) are kept apart from strategy formulation and policy setting. Absent poor performance or behavioural failure, the assumption is that managers should be deferred to. In contrast, the governed-corporation model assumes a proactive role for directors (and long-term shareholders) in the policy-making process. The goal of reforms to advance the govemed-corporation model would be to shift the role of directors from that of detached arbiters to part of an engaged team of decision makers. The current emphasis on director 'independence' in this context may well hurt board effectiveness by encouraging detachment rather than engagement. 
As Leo Strine, Chancellor of the Delaware Chancery Court points out, regulatory reforms are making it difficult for boards to include a blend of inside and outside expertise, as a range of tasks are increasingly reserved for independent directors (exacerbated by the labelling of any director having company affiliations as 'non- independent') . ${ }^{11}$ This is predicated, in part, on the implied (and, in the authors' view, mistaken) belief that no one can handle conflicts of interest, nor can they be effectively regulated as a matter of corporate law or otherwise.

At the risk of overstatement, the emerging model becomes a board comprised of a single insider - the CEO (who is deeply immersed in the corporation and has a keen interest in its immediate future) - and a number of 'independent' directors selected because they have no affiliation with, or any historical or current interest in, the corporation's business or its future. As Strine notes, 'that is an odd group to help develop a business strategy, and seems likely to function largely as a monitor, with strategy being left to be decided by the CEO and her subordinates outside of the board's presence'. ${ }^{12}$ Warren Buffett argues that the true root of corporate scandals has been boards of directors' apathy and lack of engagement. ${ }^{13}$ He dismisses the argument that board independence is a significant problem and has argued that owners, suppliers or professional advisers can often perform more effectively as directors.

The danger is that independent directors will tend to be more risk averse. At the personal level, they face much more downside risk than upside reward and (at least in the short term) are prone to lack the knowledge necessary in order to make informed 'bets'. The result is a tendency to focus on inputs (and their personal exposure) rather than outputs (and what's good for the corporation and its stakeholders).

While it may offend current fashion, there is much to be argued in favour of correcting the balance with more insiders on boards, or, at least, for thinking about knowledge as a more important factor in board composition and dynamics than independence. Interestingly, while family-controlled businesses have long been viewed as rife with conflicts, a recent study suggests that a majority of them outperform and outlast their non-family controlled peers. ${ }^{14}$

\section{DIFFERENTIATING ROLES}

If corporate governance consist of managing business operations, it is arguable whether there is an enduring role for boards of directors. A more constructive and functional approach is suggested by the works of Elliott Jaques, who took a different tack to differentiating responsibilities. After working for over 30 years in the UK as a management consultant, this Canadian-born psychologist, physician and sociologist concluded that organisational hierarchies are deeply ingrained in human nature and can be objectively measured.

The cornerstone of his theones, which resulted in more than 20 books and many journal publications, is the concept of 'time- span of responsibility'. In simple terms, every individual has some responsibility, some discretion, with regards to the manner in which their tasks are 
executed. Sooner or later, however, they will be checked upon by a 'superior' (a supervisor, a CEO, a board of directors, etc), who will determine whether they have been using the resources at their disposal wisely. The essential question, according to Jaques, is: How long does the individual exercise discretion without being checked by a superior? For manual workers, this could be minutes or hours. For lower-level managers, it may go from weeks to a month; for middle managers, from one month to one year; for top managers, several years. ${ }^{15}$ Hierarchies become a natural way to organise around ascending layers of time-spans of responsibility.

While Jaques used this finding to inspire a number of interesting works about levels of responsibility, evaluation and incentive systems, ${ }^{1}$ organisational culture and leadership, ${ }^{1}$ and even a general theory for organisation, one could well apply his basic proposition to clarify roles in corporate governance.

The starting point is Jaques' finding that the level of responsibility in any organisational role can be objectively measured in terms of the target completion time of the longest task assigned to that role. ${ }^{19}$ In today's environment, it may well be unrealistic to assign a CEO sole responsibility for tasks that will have an impact in-20 years. Markets and institutional investors impose considerable pressure on management to focus on shortterm performance. Likewise, senior management - subject to 'bounded rationality' ${ }^{20}$ — often have difficulty focusing on the longer term due to the immediate and dynamic day-to-day pressures of issues such as political and regulatory exigencies, customers' demands or competitor moves.

To take an extreme example, few would argue that a series of one-year objectives can, cumulatively, be viewed as a long-term strategy (or lead to extraordinary performance). Yet market incentives often drive such behaviour on the part of corporate managers, whose performance is measured on a quarterly and annual basis. Often, even firms with multi-year plans tend to measure only the first year's goals (which can then be reset to meet next year's bonus thresholds). In addition to fostering a short-term outlook, this tends to further encourage managers (and boards) to cling to the implicit (and deeply flawed) belief in the stability of organisations and markets - a belief that becomes a means of maintaining stability, or at any rate, the illusion of it. As Donald Schon pointed out decades ago, 'the more radical the prospect of change the more vigorous the defence — the more urgent the commitment to the stable state'. $^{22}$

Managerial theorists such as Peter Senge have observed that, as in natural systems, corporations rarely follow such a linear flow of progression. Rather, in what some have termed 'biomimicry', most successful corporations follow a cycle of rapid growth (production), temporary stability (recycling) and, when things go well, disruptive regeneration (or decline). Embracing this continuing process of transformation makes it imperative to institutionalise a longer term focus on 'organisational learning' and sustainability. As Senge observes, the major impediment to this is the fact that most management groups want things to happen quickly, well within the timeframes to which their personal rewards are geared. ${ }^{23}$

Considering the basic proposition of Jaques, it may be useful to think of the board of directors as 
occupying the highest hierarchical position - responsible for those tasks and dimensions that have the longest time-span of completion. It is here that boards might 'carve out' and clarify a more useful role for themselves. Rather than struggle with the operational primacy of management (assuming, of course, they have confidence in the CEO), they might shift the emphasis of their monitoring role - to one that would focus on maximising the company's longer-term sustainable value.

In such a model, students of Jaques would agree that boards of directors should focus on optimal organisational design. 'CEOs should be accountable for developing, implementing and maintaining superior organisational designs. Boards of Directors should be accountable for ensuring that this happens.' 24

\section{BALANCING SHORT AND LONG-TERM FOCUS}

The authors are not suggesting that the CEO gives up responsibility for either the strategic planning process or organisational alignment. Rather, this might be a primary focus in the interaction between the CEO and the board of directors (and directors should be expected to have a much deeper appreciation of their company's strategy and its elements and manner of execution than most do currently). Indeed, it is this focus that might best define and inform many of the other basic responsibilities of the boards of most large public corporations - CEO selection, evaluation and ongoing succession planning, providing a 'sounding board' for the CEO and drilling deeply in their review of major corporate transactions.

In a recent survey, ${ }^{25}$ a majority of corporate managers indicated they would forego investments that offered an attractive return on capital if it meant missing quarterly earnings expectations. Regrettably, regulatory reforms often tend to aggravate, rather than mitigate, this misperception of what financial markets want. Hence, despite a significant increase in the time commitments required of directors, most still do not grapple with the kind of strategic tradeoffs needed to strike an appropriate balance between short-term performance and long-term health.

It is alarming that the most recently released McKinsey survey of corporate directors indicated that, while more than 75 per cent wanted to spend more time on strategy and risk, more than a quarter had, at best, a limited understanding of the current strategy of their companies. ${ }^{26}$ Only 11 per cent claimed to have a complete understanding, while only 4 per cent said that they fully understood their company's long-term position and more than half indicated that they had little or no understanding of the key initiatives that their companies needed in order to secure the longterm future.

The authors recognise that the day-to-day activities of the board go beyond these topics. Their concern, however, is that the increasing focus on operational oversight tends to deflect attention from the more fundamental issues on which good directors can and should be expected to 'add value' and, all too often, leads to either superficial oversight or micromanagement.

By differentiating and focusing roles more clearly, there would be a stronger sense of purpose 
and responsibility for directors and CEOs alike (and less risk of co-option or the dependence of directors). It might facilitate the sort of 'constructive tension' between boards and management that many espouse but (until there is a crisis) far fewer achieve. Most importantly, it would provide a constructive counterpoint to the pressures imposed on management to meet immediate challenges.

Nor are the authors suggesting that the board should forsake its responsibility to monitor management performance and operations. Rather, such a differentiation might encourage a more constructive balance, carving out a proactive (versus compliance- oriented) role for the board, while recognising the operational primacy of management and encouraging directors to dedicate their primary attention to evaluating the manner in which the company can best fulfil its longterm strategy.

\section{BUILDING ORGANISATIONAL CAPACITY}

To be fair, regulatory reforms and perceived market pressures (and related compensation frameworks) are not the only reasons for management tending to be overly focused on the short term. Leaving aside such factors, it is challenging to manage multiple time horizons - to build the resilience and organisational capacity not only to deliver in the short term, but also to sustain performance. Here, again, a reflective board, prepared to take informed risks and focused on the long-term success of the enterprise, should be able to contribute value.

One of the problems with the self- correcting power of the corporate law system, is that it demands a great deal of self-conscious and intelligent moral reflection from busy, harassed people who have little time to give it and not much training in how to. Richard Neilsen characterised this problem, in part, as one of 'managerial isolation' and advocated that managers at all levels in an organisation should habitually think about the enterprise's legitimate values in the context of what it is doing or planning. ${ }^{27}$

Such organisational capacity is the key to managing in an uncertain world. Achieving a high 'learn to bum ratio' within an organisation increases the odds of success and lets a firm 'fall forward' rather than backward in response to the unanticipated challenges and setbacks that inevitably arise. ${ }^{28}$ Again, Jaques' theones of organisational design are instructive, as are others.

McKinsey, for example, suggests a number of key antidotes. ${ }^{29}$ First, it is argued that a company's strategy should consist of a portfolio of initiatives that consciously embrace different time horizons. Some initiatives will influence short-term performance, while others will create options for the future. Secondly, companies need to identify a small number of key metrics to support a focus on both performance and health. Finally, companies need to change the nature of their dialogue with key stakeholders, particularly investors and employees to promote that 'virtuous cycle' identified at the outset of this paper. There is little point, for example, in discussing the company's long-term health with arbitrageurs or most hedge fund managers. These are all measures that fall within the remit of an engaged board of directors. 


\section{FOCUS ON VALUE SUSTAINABILITY}

Once boards decide to shift their focus to maximising long-term sustainable value, they can then address how they want to structure and inform themselves to do their job better. To be effective, such a role will require boards to delve beneath the surface of corporate performance.

As a starting point, boards should eschew the US trend towards over-reliance on lengthy, detailed, highly prescriptive accounting rules. In addition to such generally accepted accounting principles (GAAP) financial statements, they should be receiving information (and hopefully, in turn, overseeing reporting to shareholders) in a manner that provides multiple perspective reporting as to how the relevant business is conceptualised, managed and performing.

This process should involve producing additional financial and non-financial reporting reflecting the various perspectives needed to create a meaningful picture of economic performance. As Litan and Wallison ${ }^{31}$ argue, GAAP have serious shortcomings in reflecting the factors that determine the value of companies with newer business models as opposed to those used 30 years ago. For example, market to book ratio was, on average, very close to 1 until the early 1980s. Hence investors could feel comfortable that accounting figures had a reasonable association to the true value of their investment. On the other hand, current valuation models take into account intangible assets associated with factors such as brands, customer base, workforce, innovation and marketing effectiveness.

Financial results tend to be lagging performance indicators, whereas factors such as customer satisfaction, product or service quality, relationships with outside stakeholders, innovation and employee commitment are leading indicators of sustainable performance. As noted above, this challenges directors to turn their attention to non- GAAP and non-financial indicators, which tend to be harder to measure and less reliable (and, accordingly, ignored if not actively discouraged by financial markets, regulators and liability regimes). Determining ways to rigorously monitor such performance measures will suggest new roles and duties for independent advisers, as well as boards of directors. It is encouraging to see the growing adoption of management control tools such as the Balanced Scorecard. This instrument, created in the early 1990s by Robert Kaplan and David Norton, was meant to provide a 'balanced' set of measures that complements the financial indicators 'with operational measures on customer satisfaction, internal processes, and the organization's innovation and improvement activities ... that are the drivers of future financial performance'. ${ }^{32}$ More recently the same authors linked the balanced scorecard framework with strategy planning, making it an even more powerful tool for boards and top managers to use to monitor risk and strategic execution.

Another issue that flows from such a focus is ongoing succession planning - a vital aspect of monitoring management performance and operations in order to evaluate the manner in which the company is fulfilling its long-term strategy and its capacity to continue to do so. Likewise, with respect to the review of transactions that could fundamentally change the company's trajectory.

A recent Booz Allen Hamilton survey found that more shareholder value was wiped out in the 
five-year period from 1999 to 2003 as a result of mismanagement and poor execution of strategy than was lost through all the recent compliance scandals combined. While a necessary instrument for risk management, few successful businesses have been built through controls. It is intuitively obvious to anyone who understands the culture of enterprise that too much focus on compliance can overwhelm the keys to corporate success - good strategy and empowered people who can execute it.

This differentiation of roles and focus may be particularly timely in today's 'zero tolerance' regulatory environment. At a time when senior managers are spending disproportionate resources focusing on immediate (if not retroactive) and often overwhelming issues of regulatory compliance, it is critical that boards take a broader view to ensure that policies and processes are put in place to make the right kind of decisions, build the right kind of culture and attract the right kind of people over time. Succumbing to overly risk-averse conduct - which may be expedient in the short term when CEOs fear the 'criminalisation of mistakes' - will needlessly impose longer-term costs at both the firm and market levels.

\section{CONCLUSION}

Never has the corporation been so challenged as a form of enterprise. For generations, it has been the primary vehicle for the diffusion of innovation and, therefore, in a major sense, a vital agent of social learning for society at large.

Whether the corporation will continue to be the central instrument in such a construct may well depend on the ability to ensure a steady hand on the tiller, focusing beyond the vagaries of today's reactionary environment, to ensure the corporation's continuing vitality as a powerful and self-regenerating mode of mobilising capital and enterprise.

The ability of the system to self-correct, over time embracing a more balanced approach to nurturing the long-term performance of corporations and promoting 'systems thinking' tools that have been available for some time, should be influenced by the success in clarifying the interlocking roles of boards and corporate management. The key is to ensure that such tools are neither applied mechanically nor squeezed out by pressures for short-term or narrow complianceoriented perspectives.

\section{REFERENCES}

1 Rebecca Harding, in 'Risky Business' (Deloitte UK, September 2005) found that over the past 10 years companies in the FTSE 100 and 250 indices whose boards focused on short-term risk management actually experienced the largest one-day drops in their share price which most have yet to see recover. In contrast, those firms/ boards which prioritised long-term strategic 
planning and investment in intangible assets, such as reputation and working practices, tended to see their valuations rebound after market crises.

2 Two interesting pieces illustrate how institutional investment has exacerbated this trend: Coffee, J. C. Jr (1991) 'Liquidity venus control: The institutional investor as corporate monitor', Columbia Law Review, 91 (6), 1277-1368; and Hoskisson, R., Hitt, M., Johnson, R. and Grossmann, W. (2002) 'Conflicting voices: The effects of institutional ownenhip heterogeneity and internal governance on corporate innovation strategies', Academy of Management Journal, 45 (4), 697-716.

3 Blair, M. M. and Stout, L. A. (1999) 'A team production theory of corporate law', Virginia Law Review, 85 (2), 248-328.

4 Davis, S. (2003) 'Re-inventing enterprise: The first and next decade of the global corporate governance revolution', paper presented at the Swedish Corporate Governance Forum, Stockholm, 11th December.

$5 \quad$ Ibid, at 9.

6 The first joint stock corporation was chartered in 1555. Scott, W. R. (1910-12) The

Constitution and Finance of English, Scottish and Irish Joint Stock Companies to 1720 (Cambridge), ii, 37 Cambridge University Press, Cambridge, UK.

$7 \quad$ Cheyney, E. P. (1907) 'Some English conditions surrounding the settlement in Virginia', American Historical Review, xii, 512, argues that 'the whole advance of English discovery, commerce, and colonization in the sixteenth and early seventeenth centuries was due not to individuals, but to the efforts of corporate bodies'.

8 Goodfriend, M. and MacDennott. J. (I 'Early development', American Economic lie view, 85 (1), 116-133.

9 Blair, M. (2004) 'Reforming corporate governance: What history can teach us', Berkeley Business Law Journal, Vol. 1 (1), 1-44.

10 Pound, J. (1995) 'The promise of the governed corporation', Harvard Business Review, March-April, 89.

11 Lecture delivered by Leo. E. Strine, Jr., Vice Chancellor of the Delaware Court of Chancery, to the European Policy Forum, London, 5 July, 2005. Copy of lecture text available from authors on request.

12 Ref. 4 above, at 11.

13 See (2003) 'Buffett Blames Boardroom Apathy', Investor Relations Business, 8 (6), 7.

14 Miller, D. and Le Breton-Miller, I. (2005) Managingfor the Long Run, Harvard Business School Press, Cambridge, MA.

15 Jaques, E. (1956)The Measurement of

Responsibility: A Study of Work, Payment and Individual Capacity, Harvard University Press, Cambridge, $M A$.

16 Jaques, E. (1967) The Equitable Payment, Heinemann, London, UK.

17 Jaques, E. (1988) SST: A Briefing Book for CEO's Corporate Organization and Leadership, $A B C$, New York, NY.

18 Jaques, E. (1976) A General Theory of Bureaucracy, Gregg Revivals, Aldershot, UK. Jaques, E. (1997) Requisite Organization: A Total System for Effective Managerial Organization and Managerial Leadership for the 21st Century, Cason Hall \& Co Publishers, Arlington, VA. 
19 Jaques, E. (1990) 'In praise of hierarchy', Harvard Business Review, January-February, 122.

20 Simon, H. A. (1976) Administrative Behaviour: A Study of Decision-Making Processes in Administrative Organization, Free Press, New York, NY.

21 Yet, less than 15 per cent of companies routinely track how they perform over how they thought they were going to perform. Instead, only the first-year goals are measured, according to a survey of senior executives at 197 companies conducted by Marakon Associates and the Economist Intelligence Unit (2005). 'Three Reasons Why Good Strategies Fail: Execution, Execution.. Knowledge@ Wharton, July, available at www.knowledge.wharton.upenn. edu/index.cfm?fa= printArticle \&ID=1252.

22 Schon, D. A. (1971) Beyond the Stable State, Random House, New York, NY.

23 Senge, P. M. and Carstedt, G. (2001) 'Innovating our way to the next industrial revolution', MIT Sloan Management Review, Winter, 24.

24 Claude Lamoureaux, quoted in Capelle Associates Inc. Newsletter (Volume 1/1), available at www.capelleassociates.com.

25 Graham, J.R., Harvey, D. R. and Rajgopal, S. (2005) 'The Economic Implications of Corporate Financial Reporting', NBER Working Paper No. 10550, 11th January.

26 Felton, R. F. and Keenan Fritz, P. (2005) 'The view from the boardroom', The McK-insey Quarterly, Special Edition: Value and Performance, 1 March, 48-61.

27 Neilsen, R.(1984) 'Toward an action philosophy for managers based on Arendt and Tillich', Journal of Business Ethics, 3(2), 153-161.

28 Ghemawat,P. and Pisano, G. (1997) 'Sustaining Superior Performance: Commitments and Capabilities', Harvard Business School case note no. 9-798-008, 31 st July.

29 Davis, I. (2005) 'How to escape the short-term trap'. Financial Times, 11th April; and Dobbs, R., Leslie, K. and Mendonca, L. T. (2005) 'Building the healthy corporation', The McKinsey Quarterly, 3.

30 See Pollock, A. J. (2005) 'From Making Judgements to Following Rules: The Evolution of U.S. Accounting', American Enterprise Institute Financial Services Outlook, July.

31 Litan, R. E. and Wallison, P. J. (2001) 'The GAAP Gap: Corporate Disclosure in the Age of the Internet', AEI Bookings Joint Center for Regulatory Studies; and (2003) 'Beyond GAAP', Regulation, 26 (3), 50-55.

32 Kaplan, R. and Norton, D. (1992) 'The balanced scorecard: Measures that drive performance'. Harvard Business Review, January-February, 70 (1), 71.

33 See Kaplan, R. and Norton, D. (1996) 'Using the balanced scorecard as a strategic management system', Harvard Business Review, January-February, 74 (1), 75-85; and (2000) The Strategy-Focused Organization: How Balanced Scorecard Companies Thrive in the New Business Environment, Harvard Business School Press, Cambridge, MA. 